\title{
Adenotonsillotomy resolving snoring ameliorates blood pressure and vascular structure in children - a preliminary report
}

\author{
Małgorzata Barbara Stańczyk ${ }^{1,2}$, Piotr Raczyński³ ${ }^{3}$ Jarosław Andrzejewski ${ }^{4}$, Anna Mazurek-Kula ${ }^{5}$, \\ Katarzyna Ostrowska ${ }^{5}$, Wiesław Konopka ${ }^{6,7}$, Marcin Tkaczyk ${ }^{1,7}$ \\ 'Department of Paediatrics, Immunology, and Nephrology, Polish Mother's Memorial Hospital Research Institute, Lodz, Poland \\ ${ }^{2}$ Department of Paediatrics, Preventive Cardiology, and Immunology of Developmental Age, Medical University of Lodz, \\ Lodz, Poland \\ ${ }^{3}$ Department of Imaging Diagnostics, Polish Mother's Memorial Hospital Research Institute, Lodz, Poland \\ ${ }^{4}$ Department of Paediatric Otolaryngology, Audiology, and Phoniatrics, Medical University of Lodz, Lodz, Poland \\ ${ }^{5}$ Department of Cardiology, Polish Mother's Memorial Hospital Research Institute, Lodz, Poland \\ ${ }^{6}$ Department of Otolaryngology, Polish Mother's Memorial Hospital Research Institute, Lodz, Poland \\ ${ }^{7}$ Chair and Department of Paediatrics, Preventive Cardiology, and Immunology of Developmental Age, Medical University \\ of Lodz, Lodz, Poland
}

\section{ABSTRACT}

Introduction: Adenotonsillar hypertrophy in children is the most common cause of sleep disordered breathing, which can have an impact on the cardiovascular system. The aim of the study was to assess blood pressure and carotid intima-media thickness in snoring children before and after surgery to restore patency of the upper airways.

Material and methods: In the prospective study 50 snoring children were involved (median age 7 years), who were qualified for adenotonsillotomy. They were assessed before the surgery and three and six months after. The control group comprised of 20 healthy children who were assessed once. The severity of snoring was based on a questionnaire filled in by the children's parents. The results of office blood pressure measurements, ambulatory blood pressure monitoring, and common carotid arteries intima-media thickness (cIMT) were analysed. Results: At baseline there were no differences between the study and the control group according to the casual systolic (SBP) and diastolic blood pressure (DBP) ( $z$-score SBP 0.043 vs. $-0.35, p=0.7551 ; z$-score DBP -0.07 vs. $-0.51, p=0.2232$ ). After three and six months from the surgery casual blood pressure decreased significantly in the study group ( $z$-score SBP 0.043 vs. -0.187 vs. $-0.761, p=0.0004 ; z$-score DBP -0.07 vs. -0.22 vs. $-0.41, p<0.0001$, respectively). There was a significant decrease of the mean ambulatory blood pressure after the surgery $(p=0.0393)$. Baseline cIMT was significantly greater in the study group compared to the controls (left cIMT $0.052 \mathrm{~cm}$ vs. $0.045 \mathrm{~cm}, p=0.0015$, right cIMT $0.053 \mathrm{~cm}$ vs. $0.050 \mathrm{~cm}, p=0.0162$ ). After intervention, cIMT decreased significantly.

Conclusions: Children snoring due to upper airways lymphoid tissue hypertrophy are normotensive but present features of subclinical vascular damage. Surgical intervention lowers the blood pressure and ameliorates arterial structure. The improvement of night breathing pattern is beneficial for the circulatory system.

\section{KEY WORDS:}

blood pressure, child, carotid intima-media thickness, snoring.

\section{ADDRESS FOR CORRESPONDENCE:}

Małgorzata Barbara Stańczyk, Department of Paediatrics, Immunology, and Nephrology, Polish Mother's Memorial Hospital Research Institute of Lodz, 281/289 Rzgowska St., 93-338 Lodz, Poland, ORCID: 0000-0001-6613-1642, e-mail: mbstanczyk@gmail.com 


\section{INTRODUCTION}

Sleep disordered breathing (SDB) has a well-reported association with cardiovascular risk in adults [1]. Individuals with the most severe form of SDB - obstructive sleep apnoea (OSA) can develop early signs of atherosclerosis and subclinical vascular damage [2]. The intensity of the vascular changes correlates with the severity of SDB [3]. In children, the influence of long-lasting and recurrent SDB on blood pressure and vascular damage remains elusive [4-6].

Unlike adults, in whom OSA is mainly associated with obesity, in the youngest children the most common cause of SDB is adenoid or tonsillar hypertrophy [7]. Severe OSA in children with adenoid or tonsillar hypertrophy is an absolute indication for their excision, i.a. due to hypoacusis, risk of developmental delay, and possible cardiovascular damage. From the clinical point of view, the decision of surgery is based mostly on clinical experience. Few centres perform polysomnography. Persistency of even mild sleep hypoxia can presumably lead to negative changes in the circulatory system similar to those occurring in the course of OSA. Assessment of the circulatory system before and after adenotonsillotomy can reveal to what extent parent-reported SDB in children actually affects its structure and function. Better understanding of associations in this field can be an important factor for making proper decisions that are significant for the child's health. The aim of the study was to assess the impact of a successful surgical adenotonsillectomy in snoring children on blood pressure and blood vessel structure in children with nasopharyngeal area lymphoid tissue hypertrophy.

\section{MATERIAL AND METHODS}

The study was a prospective assessment of changes in blood pressure and carotid intima-media thickness that occurred after restoring patency of upper airways after adenotonsillotomy. The study group comprised 50 children (age median seven years) with nasopharyngeal lymphatic tissue hypertrophy, who were qualified for the surgery on a clinical basis (i.e. severe SDB, recurrent infections, hypoacusis). Children from the study group were assessed before the surgery (at least one week earlier and after a period of SDB lasting for at least six months) and three and six months after the surgery. The severity of SDB was based on the questionnaire filled in by the parents. The query contained the questions about clinical signs and symptoms and the results of adenoid or tonsillar hypertrophy: heavy breathing during sleep connected with snoring, pauses in breathing, frequent arousals, excessive sweating, bed wetting, and constant breathing with open mouth. We excluded children with unstable clinical condition, acute infection, diagnosis of chronic kidney disease stage $3-5$, secondary hypertension, cardiac or vascular defect that could have an impact on measured parameters or affect study procedures, diabetes mellitus, congenital metabolism disorders (e.g. hypercholesterolae$\mathrm{mia}$ ), and other chronic diseases or medications intake that could affect blood pressure.

The comparative group comprised of 20 age- and sexmatched healthy children. The main qualifying criterion was lack of SDB and impaired patency of upper airways at least six months before taking part in the study.

The Local Bioethical Committee approved the study protocol. All the caregivers gave informed consent for the protocol and study procedures.

The groups were similar according to the basic anthropometrical parameters. The group characteristics are presented in Table 1.

Blood pressure was measured with the standard methodology using an oscillometric device (Mindray VS-800) according to the Polish epidemiological studies [8] and the $4^{\text {th }}$ report [9] methodology. Four measurements were performed on the right arm. The first result was excluded, and from the remaining measurements the mean value was calculated. Absolute and $z$-score values of the systolic (SBP) and diastolic (DBP) blood pressure were analysed. Results were referred to the normative values of Polish children $[8,10,11]$.

24-hour ambulatory blood pressure monitoring (ABPM) was performed according to the AHA methodology [12]. Typical activity during the day was recommended. The ranges of the daytime and night-time hours were established due to the normal schedule of the study participants. The result of ABPM provided the values of mean systolic and diastolic blood pressure, mean ambu-

TABLE 1. Characteristics of groups

\begin{tabular}{|l|c|c|c|}
\hline Baseline & $\begin{array}{c}\text { The study group } \\
(n=50)\end{array}$ & $\begin{array}{c}\text { The control group } \\
(n=20)\end{array}$ & $p$ \\
\hline Sex (boys), $n / n$ total (\%) & $34 / 50(68.00)$ & $7 / 20(35.00)$ & 0.0236 \\
\hline Age & $7.00(6.00-8.00)$ & $8.00(7.00-10.50)$ & 0.1059 \\
\hline$z$-score of body mass index & $0.37(-0.68-1.57)$ & $-0.16(-0.47-0.44)$ & 0.2687 \\
\hline$z$-score of height & $-0.08(-0.06-0.17)$ & $0.26(-0.30-1.05)$ & 0.1668 \\
\hline$z$-score of weight & $0.04(-0.44-1.44)$ & $-0.17(-0.46-0.85)$ & 0.6286 \\
\hline
\end{tabular}

Values presented as median and interquartile ranges ( $\left(1^{\text {st }}\right.$ and $3^{\text {rd }}$ quartile) 
latory blood pressure, and night-time dipping of blood pressure. The results were referred to the normative values calculated by German researchers in 2002 [13].

Common carotid arteries intima-media thickness (cIMT) was measured in ultrasound examination in the two-dimensional mode with a HD11XE Philips device provided with a linear head of $12 \mathrm{MHz}$ frequency. The cIMT measurements were taken according to the standards of the Mannheim intima-media thickness consensus [14]. Results were referred to the standards for 6-18-yearold children published in 2013 by Doyon et al. [15].

\section{STATISTICAL ANALYSIS}

The normality of distribution of the variables was assessed with the Shapiro-Wilk test. Differences in the frequency of distribution were assessed by the $\chi^{2}$ test. Medians with interquartile ranges or means with standard deviations were applied according to the distribution of variables. To assess the changes caused by the surgery ANOVA or Friedman's ANOVA were used depending on the distribution of the variables. Correlations between variables were assessed by Spearman's or Pearson's correlation coefficient depending on the distribution of the variables. The size of the study group was assessed (power analysis test) according to a drop of blood pressure by $4 \mathrm{~mm} \mathrm{Hg}$. The $p$-values below 0.05 were considered statistically significant.

\section{RESULTS}

Casual blood pressures (BP) of children from the study group were within normal ranges and were comparable to the controls at each stage of the study. At baseline only three children (3\%) had $z$-score values of BP higher than +2.0 SD.

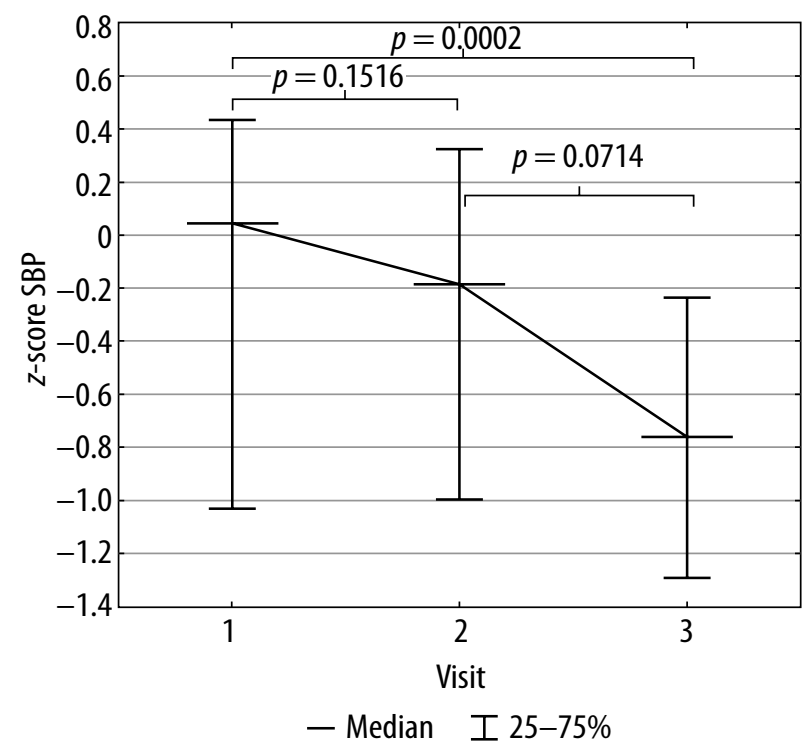

FIGURE 1. Changes of systolic blood pressure (SBP) $z$-score after surgery in the study group, $p=0.0004$ (ANOVA)
BP of children from the study group decreased significantly after the surgery: $\operatorname{SBP}(p=0.0004), \operatorname{DBP}(p<0.0001)$, and mean arterial blood pressure (MAP) $(p=0.0022)$. $Z$-score of SBP significantly decreased between baseline and six months after the surgery (Fig. 1), and $z$-score of DBP decreased three months after the surgery $(p=0.0009)$ (Fig. 2). Similarly, absolute values of MAP decreased three months after the surgery $(p=0.0323)$.

None of the children after the surgery had abnormal BP values (Table 2 ).

The daytime DBP at baseline was significantly higher in children from the study group compared to the controls $(p=0.0102)$, but there were no differences according to the daytime SBP $(p=0.1122)$ (Table 2). After the surgery, values of both daytime BP components decreased - it was significant only six months after the surgery ( $p=0.0009$ and $p=0.0235$, respectively). The night-time BP did not change significantly during the observation. No differences in daytime and night-time BP were noted after surgery between the study and the control group.

At baseline, the difference between mean ambulatory blood pressure in both groups was near significance $(p=0.0630)$. After the surgery it dropped significantly $(p=0.0393)$.

At baseline nocturnal dipping of SBP and DBP in the study group was not different compared to the controls. Nocturnal dipping of SBP was smaller after the surgery $(p=0.0055)$. Six months after the surgery SBP nocturnal dipping was significantly smaller compared to the control group ( $p=0.0264$ ). There were no significant changes of DBP nocturnal dipping after the surgery (Table 2).

At baseline cIMT bilaterally was significantly greater in the study group compared to the controls (left cIMT $p=0.0015$, right cIMT $p=0.0162)$. After surgery the cIMT in the study group bilaterally decreased $(p=0.0028$ and $p=0.0021$, respectively). Reduction of thickness was

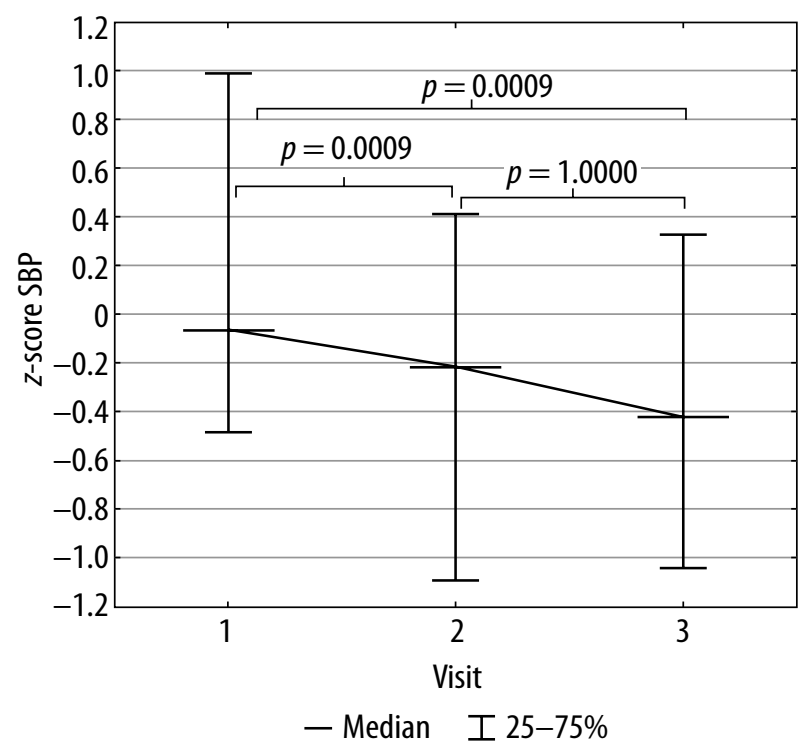

FIGURE 2. Changes of diastolic blood pressure (DBP) $z$-score after surgery in the study group, $p<0.0001$ (ANOVA) 
TABLE 2. Casual blood pressure, ambulatory blood pressure monitoring results, and common carotid intima-media thickness in the study and control group

\begin{tabular}{|c|c|c|c|c|c|c|c|c|}
\hline \multirow[t]{2}{*}{ Characteristic } & \multicolumn{3}{|c|}{ Study group } & \multirow{2}{*}{$\begin{array}{c}p \\
1 / 2 / 3\end{array}$} & \multirow{2}{*}{$\begin{array}{l}\text { Control } \\
\text { group (C) }\end{array}$} & \multicolumn{3}{|c|}{$p$} \\
\hline & $\begin{array}{c}\text { Before } \\
\text { surgery (1) }\end{array}$ & $\begin{array}{c}3 \text { months after } \\
\text { surgery (2) }\end{array}$ & $\begin{array}{c}6 \text { months after } \\
\text { surgery (3) }\end{array}$ & & & $1 / C$ & $2 / C$ & $3 / C$ \\
\hline SBP, z-score & $\begin{array}{c}0.043 \\
(-1.03-0.43) \\
\end{array}$ & $\begin{array}{c}-0.187 \\
(-1.00-0.32) \\
\end{array}$ & $\begin{array}{c}-0.761 \\
(-1.29-[-0.24]) \\
\end{array}$ & 0.0004 & $\begin{array}{c}-0.35 \\
(-1.14-0.21) \\
\end{array}$ & 0.7551 & 1.0 & 0.6087 \\
\hline $\mathrm{SBP}(\mathrm{mm} \mathrm{Hg})$ & $\begin{array}{c}101 \\
(93-105) \\
\end{array}$ & $\begin{array}{c}100.5 \\
(95-105.5) \\
\end{array}$ & $\begin{array}{c}97 \\
(92-101) \\
\end{array}$ & 0.0703 & $\begin{array}{c}98 \\
(91-105.5) \\
\end{array}$ & 1.0 & 1.0 & 1.0 \\
\hline DBP, z-score & $\begin{array}{c}-0.07 \\
(-0.48-0.99)\end{array}$ & $\begin{array}{c}-0.22 \\
(-1.09-0.41)\end{array}$ & $\begin{array}{c}-0.41 \\
(-1.04-0.33)\end{array}$ & $<0.0001$ & $\begin{array}{c}-0.51 \\
(-1.2-0.2) \\
\end{array}$ & 0.2232 & 1.0 & 1.0 \\
\hline $\mathrm{DBP}(\mathrm{mm} \mathrm{Hg})$ & $\begin{array}{c}59 \\
(54-65) \\
\end{array}$ & $\begin{array}{c}59 \\
(53-62.5) \\
\end{array}$ & $\begin{array}{c}57 \\
(53-62) \\
\end{array}$ & 0.0006 & $\begin{array}{c}57 \\
(53.5-60.1) \\
\end{array}$ & 0.4473 & 1.0 & 1.0 \\
\hline MAP (mm Hg) & $\begin{array}{c}73 \\
(63.33-79) \\
\end{array}$ & $\begin{array}{c}72.17 \\
(67.33-76) \\
\end{array}$ & $\begin{array}{c}69.67 \\
(66.33-73.67) \\
\end{array}$ & 0.0022 & $\begin{array}{c}70.5 \\
(66.83-74.67) \\
\end{array}$ & 0.5790 & 1.0 & 1.0 \\
\hline $\mathrm{dSBP}(\mathrm{mm} \mathrm{Hg})$ & $\begin{array}{c}113 \\
(107-123.8) \\
\end{array}$ & $\begin{array}{c}110.2 \\
(107.2-114) \\
\end{array}$ & $\begin{array}{c}106 \\
(102.1-110.5) \\
\end{array}$ & 0.0009 & $\begin{array}{c}108.10 \\
(101.35-124.5) \\
\end{array}$ & 0.1122 & 0.459 & 1.0 \\
\hline $\mathrm{dDBP}(\mathrm{mm} \mathrm{Hg})$ & $\begin{array}{c}69 \\
(63-73) \\
\end{array}$ & $\begin{array}{c}65.9 \\
(63.5-70.45) \\
\end{array}$ & $\begin{array}{c}66 \\
(63.8-68.5) \\
\end{array}$ & 0.0235 & $\begin{array}{c}66.35 \\
(64.65-68.65) \\
\end{array}$ & 0.0102 & 1.0 & 1.0 \\
\hline $\mathrm{nSBP}(\mathrm{mm} \mathrm{Hg})$ & $\begin{array}{c}98 \\
(91.4-105.7) \\
\end{array}$ & $\begin{array}{c}97.5 \\
(94-102) \\
\end{array}$ & $\begin{array}{c}98.8 \\
(92.9-104) \\
\end{array}$ & 0.6444 & $\begin{array}{c}95.2 \\
(91.3-97.8) \\
\end{array}$ & 0.3438 & 0.393 & 0.2772 \\
\hline $\mathrm{nDBP}(\mathrm{mm} \mathrm{Hg})$ & $\begin{array}{c}55 \\
(52-59.3) \\
\end{array}$ & $\begin{array}{c}55.85 \\
(52-60) \\
\end{array}$ & $\begin{array}{c}56 \\
(52-58) \\
\end{array}$ & 0.7247 & $\begin{array}{c}55.6 \\
(53.25-57.75) \\
\end{array}$ & 1.0 & 1.0 & 1.0 \\
\hline Dipping SBP (\%) & $\begin{array}{c}12.15 \\
(8.25-15.93) \\
\end{array}$ & $\begin{array}{c}11.26 \\
(7.73-14.29) \\
\end{array}$ & $\begin{array}{c}9.17 \\
(6.35-11.32) \\
\end{array}$ & 0.0055 & $\begin{array}{c}12.42 \\
(9.98-14.26) \\
\end{array}$ & 0.0522 & 1.0 & 0.0264 \\
\hline Dipping DBP (\%) & $\begin{array}{c}17.46 \\
(13.56-3.76) \\
\end{array}$ & $\begin{array}{c}16.79 \\
(10.69-19.87) \\
\end{array}$ & $\begin{array}{c}15.71 \\
(10.29-20.31) \\
\end{array}$ & 0.1236 & $\begin{array}{c}16.16 \\
(14.16-19.37) \\
\end{array}$ & 1.0 & 1.0 & 0.0552 \\
\hline $\begin{array}{l}\text { Mean ambulatory } \\
\text { blood pressure }\end{array}$ & $\begin{array}{c}77.17 \\
(73.8-82.67) \\
\end{array}$ & $\begin{array}{c}75.88 \\
(73.42-81.05) \\
\end{array}$ & $\begin{array}{c}75.23 \\
(73.27-79.53) \\
\end{array}$ & 0.0393 & $\begin{array}{c}75.97 \\
(72.35-78.37) \\
\end{array}$ & 0.0630 & 1.0 & 1.0 \\
\hline I IMT (cm) & $\begin{array}{c}0.052 \\
(0.049-0.057) \\
\end{array}$ & $\begin{array}{c}0.049 \\
(0.046-0.052) \\
\end{array}$ & $\begin{array}{c}0.047 \\
(0.045-0.050) \\
\end{array}$ & 0.0028 & $\begin{array}{c}0.045 \\
(0.040-0.049) \\
\end{array}$ & 0.0015 & 0.1966 & 0.2028 \\
\hline rIMT $(\mathrm{cm})$ & $\begin{array}{c}0.053 \\
(0.050-0.056) \\
\end{array}$ & $\begin{array}{c}0.048 \\
(0.045-0.052) \\
\end{array}$ & $\begin{array}{c}0.048 \\
(0.046-0.050) \\
\end{array}$ & 0.0021 & $\begin{array}{c}0.050 \\
(0.041-0.051) \\
\end{array}$ & 0.0162 & 1.0 & 1.0 \\
\hline
\end{tabular}

$S B P$ - systolic blood pressure, DBP - diastolic blood pressure, MAP - mean arterial blood pressure, dSBP - daytime systolic blood pressure, dDBP - daytime diastolic blood pressure, $n S B P$ - night-time systolic blood pressure, $n D B P$ - night-time diastolic blood pressure, dipping SBP - nocturnal dipping of systolic blood pressure, dipping DBP - nocturnal dipping of diastolic blood pressure, IIMT - left common carotid intima-media thickness, $r$ IMT - right common carotid intima-media thickness. Values presented as median and interquartile ranges ( $1^{5 t}$ and $3^{\text {rd }}$ quartile). Significance showed for the study group (1/2/3) and for every stage in comparison with the control group $(1 / C, 2 / C, 3 / C)$

clearly visible three months after the surgery $(p=0.0441$ and $p=0.0183$, respectively). There was no difference between cIMT in the study and control groups in the third and sixth months after the surgery (Table 2).

The analysis of correlations in the study group revealed that the changes of DBP and BMI $z$-scores after surgery correlated positively $(R=0.31, p=0.0332)$. The change of SBP $z$-score after surgery was negatively correlated with baseline DBP $z$-score $(R=-0.40, p=0.0068)$. Assessment of correlations between systolic and diastolic blood pressure and cIMT revealed that only the change in the $z$-score of SBP after surgery was negatively correlated with baseline $\operatorname{cIMT}(R=-0.31, p=0.0363)$.

\section{DISCUSSION}

The study revealed that children snoring due to adenoid or tonsillar hypertrophy are mostly normotensive.
However, it showed that some symptoms of vascular damage might be present and, what is of greater importance, could be reversed by an effective surgery. In Polish epidemiological studies on normative values of BP children snoring due to adenoid or tonsillar hypertrophy were not excluded, as far as they did not have other conditions affecting blood pressure [11]. The children from the present study, apart from nasopharyngeal lymphoid tissue hypertrophy, were completely healthy. Thus, their blood pressure can reflect a distribution of this feature in the whole child population, especially after considering that snoring affects as much as $25 \%$ of this population [16].

According to the available data, OSA can have a negative impact on BP, while for milder forms of SDB this is not necessarily the case $[5,17,18]$. However, most studies on the effect of SDB on the circulatory system were not prospective. Moreover, the majority of them compared absolute values of $\mathrm{BP}$, which makes interpretation 
of the results difficult in different age groups. To avoid this problem in the present study the BP $z$-scores were compared.

In the aspect of SDB severity, some studies were based only on the query addressed to the parents, in others objective polysomnographic assessment was performed. Kaditis et al. compared BP between habitually snoring and healthy children using similar a methodology to the one presented herein and obtained similar results [19]. According to the authors, children with habitual snoring do not have higher BP than non-snorers [19]. Marshall et al., in the CAPS study (Childhood Asthma Prevention Study) [5], also did not assess SDB objectively - the presence and frequency of snoring were assessed on the basis of a questionnaire filled in by parents. Also, as in the previously mentioned study, there was no proof that parent-reported snoring in children is related to higher BP [5]. Because left heart ventricle hypertrophy is a known complication of hypertension, normal left ventricular parameters assessed by echocardiography in snoring children correspond to their normal blood pressure [20]. In children with OSA the relationship with higher BP seems to be better proven [21,22]. However, not all authors agree about the negative impact of OSA on blood pressure [23]. Studies with polysomnographic assessment revealed that non-obese children are normotensive despite the severity of SDB [24]. This conclusion questions the importance of a direct impact of SDB on BP, bringing up the disturbed body composition as the main cause of blood pressure abnormalities, but not sleep hypoxia itself.

Data about the impact of surgical treatment on BP in children snoring due to adenoid or tonsillar hypertrophy are scarce and incoherent. Prospective studies assessed mainly changes in BP of children in whom polysomnography had proven the presence of OSA. According to some authors, only thin children can have truly important benefits for BP from surgery [25]. Our study revealed that the change of body mass index (BMI) $z$-score positively correlated with the change of DBP, which remains in contrast to other authors' observations. Nevertheless, it is coherent with the evidence that the lower the body weight, the lower the BP. Hence it seems that for the optimal effect of adenotonsillotomy simultaneous weight loss is also justified.

Previous studies did not confirm clearly that surgery could have a beneficial impact on BP in children with SDB. Some authors claim that the surgery has no influence on BP despite the improvement of sleep quality [26]. Some even suggested that the conservative treatment can bring similar effects on $\mathrm{BP}$ as the surgery in longer observation [27]. According to some authors, while the surgery can substantially reduce severity of the symptoms of SDB, a significant change in $\mathrm{BP}$ can be observed only in hypertensive children [28]. In the present study we observed that the drop of blood pressure was more pronounced in children with higher baseline $z$-score of BP. This suggests that in fact the surgery can be more beneficial for children with higher baseline BP.

For better recognition of the impact of SDB on blood pressure, we performed ABPM assessment, which revealed that in children snoring due to lymphoid tissue hypertrophy, during the daytime only baseline DBP was higher compared to non-snorers. Such results are partly coherent with the results presented by other researchers. Most of the observations conducted in children with well-documented sleep apnoea report that BP assessed in ABPM differs throughout the day and the night between the children with symptoms of SDB and those without them. Some studies showed that SDB is mostly connected with elevated DBP, which is most evidently marked between children with OSA and primary snoring [29]. However, some authors demonstrated such a difference only in the night-time [30]. In other studies in children with sleep apnoea, higher BP was present throughout the day and night [31,32]. The severity of SDB determined the level of BP. Moreover, these data suggest that nighttime DBP in children with habitual snoring was significantly higher in comparison with children without SDB. Thus, snoring in children should not be considered only as a mild disorder not requiring treatment [33]. In the present study the night-time BP in children did not differ from non-snorers. However, the tendency for higher mean ambulatory blood pressure values was marked in snorers compared to non-snorers, which justifies similar conclusions that snoring is more than just a mild symptom that does not require treatment. The studies showed that restoring patency of the upper airways decreases the DBP assessed in ABPM [34]. Our study revealed a similar change, which was recognised six months after the surgery.

Studies among adults showed that reduction of nocturnal dipping and higher night-time $\mathrm{BP}$ is related to higher risk of adverse cardiovascular events in the future [35]. This can be explained by the constant exposition of blood vessels and target organs on higher BP. In adults the nocturnal dipping rate is associated with sleep quality - shallow and interrupted sleep effects with too small dipping [36]. Adults with OSA are mostly non-dippers [37]. Studies among children do not fully confirm the association between SDB and the loss of nocturnal dipping [38]. The present study showed that nocturnal dipping in children snoring due to the upper airway obstruction was relevant $(\geq 10 \%)$ and comparable with the control group. Only six months after surgery the systolic nocturnal dipping was a bit too small, which reflected the lowering of BP that occurred only in the daytime. According to some research the lack of nocturnal dipping loss can be explained by an overly short period of SDB [38]. However, it does not exclude the thesis that persistence of these disturbances increase the cardiovascular risk in the future. The authors postulate that pre-school age, when the damage of blood vessels is barely marked, could be 
the optimal moment for early removal of the potentially harmful effects of SDB on the circulatory system [38].

The results showing positive changes in cIMT strongly confirm the beneficial effect of surgery resolving snoring for circulatory system conditions. cIMT is an indirect indicator of subclinical vascular damage in the course of hypertension. The present study revealed that the median cIMT at the beginning of the study exceeded $95^{\text {th }}$ percentile according to the standards accepted for children [15]. These observations justify the conclusion that snoring children might have features of subclinical vascular damage.

From the studies in adults it arises that self-reported snorers have a significantly greater cIMT than non-snorers [39]. To date, there are no data showing that snoring in children negatively affects cIMT, as presented in our study. The available studies conducted in child populations reported no increase of cIMT in relation to snoring $[5,40]$. An important observation arising from the present study is the positive result of surgery restoring the patency of the nasopharyngeal area, which led to a significant decrease of cIMT after treatment. Such a change could be an expression of better nocturnal oxygenation and lack of permanent dysregulation in the collagen and elastin balance of the vascular wall. Higher BP causes wall thickening, which prevents excessive tissue flow [41]. At early stages vascular wall stiffness remains normal due to an increase of the amount of elastic fibres and structural remodelling of the muscle membrane. This is a sign of adaptation to the new conditions. Later, this compensation potential decreases. In individuals with hypertension, increased luminal pressure stimulates excessive collagen production, which contributes to the vascular stiffness [42]. The improvement we observed after surgery suggests that the thickening of cIMT had not yet been permanent enogh to result in arterial wall remodelling. Although the children in the present study were generally normotensive, along with the observation that blood pressure and cIMT decreased after surgery, there is a strong suggestion that snoring was not insignificant for their arterial structure.

As discussed earlier, strong data exist on OSA having an impact on circulatory system condition. According to the latest data more than a half of habitually snoring children have OSA or upper airway resistance syndrome [43]. The suspicion of severe SDB arising from the history taken from parents of snoring children is an indication to the polysomnography, which should confirm the diagnosis of OSA. The study by Øverland et al. conducted in 2-6-year-old children referred to adenotonsillectomy did not support the idea about the utility of questionnaires as tools to identify OSA. Only physical examination was weakly associated with OSA; nevertheless, polysomnography remains the method of choice for the diagnosis [44]. According to other studies, also hypertension can be a predictor of the presence of OSA in snoring children.
Malakasioti et al. showed that systolic hypertension was a significant predictor of moderate-to-severe OSA and indicated the importance of referral for polysomnography to rule out OSAS [45]. However, numerous of laryngological centres do not have access to polysomnography, or testing availability is insufficient. Therefore, in many cases the possibility of quick diagnosis of OSA is poor, which can delay proper clinical management of the patient. The other absolute indications for the surgery are possible to be justified and confirmed in clinics, departments, or ambulatory laryngological care units, severity of SDB in our reality is determined on the basis of the history taken from the parents - it is very rarely verified (if at all) by specialistic sleep assessment. Hence, the result of the present study, despite a lack of objective measurement of SDB severity, can have an important impact on the clinical approach. In the study we have proven that parents' reported severity of SDB in their children can be converted into the degree of the health burden. In light of the results, and considering that snoring can last for years, long-lasting exposure of the circulatory system to permanent hypoxia can result in a slow but accelerating process of cardiovascular damage.

The main limitation of the study is that the comparative group comprised of only 20 healthy children, which could cause underestimation of the differences between both the study and the control group at the baseline assessment. Although after surgery we observed a significant drop in blood pressure of children from the study group, we could not prove that at baseline both groups differed in blood pressure values. However, the results concerning cIMT showed a significant difference between both groups at baseline, which disappeared after the surgery. The optimal way to confirm our results would be to reconstruct the study design making the control group equally numerous and assessing also at three time points - similarly to the children from the study group. Therefore, we present the study results as a preliminary report.

\section{CONCLUSIONS}

The study revealed that children snoring due to hypertrophy of the upper airways lymphoid tissue, although normotensive, can present features of subclinical vascular damage. The drop in blood pressure and decrease in cIMT after the surgery indicate that improvement of the night breathing pattern is beneficial for the circulatory system. Parents' reported snoring in children might be an important item of pre-surgery assessment. When polysomnographic assessment is unavailable it can be an important premise of adenoid or tonsillar excision.

\section{DISCLOSURE}

The authors declare no conflict of interest. 


\section{REFERENCES}

1. Niiranen TJ, Kronholm E, Rissanen H, et al. Self-reported obstructive sleep apnea, simple snoring, and various markers of sleepdisordered breathing as predictors of cardiovascular risk. Sleep Breath 2016; 20: 589-596.

2. Baguet J-P, Nadra M, Barone-Rochette G, et al. Early cardiovascular abnormalities in newly diagnosed obstructive sleep apnea. Vasc Health Risk Manag 2009; 5: 1063-1073.

3. Atkeson A, Yeh SY, Malhotra A, et al. Endothelial function in obstructive sleep apnea. Prog Cardiovasc Dis 2009; 51: 351-362.

4. Nisbet LC, Yiallourou SR, Biggs SN, et al. Preschool children with obstructive sleep apnea: the beginnings of elevated blood pressure? Sleep 2013; 36: 1219-1226.

5. Marshall NS, Ayer JG, Toelle BG, et al. Snoring is not associated with adverse effects on blood pressure, arterial structure or function in 8-year-old children: the Childhood Asthma Prevention Study (CAPS). J Paediatr Child Health 2011; 47: 518-523.

6. Abdel-Aziz M. Asymptomatic cardiopulmonary changes caused by adenoid hypertrophy. J Craniofac Surg 2011; 22: 1401-1403.

7. Chang SJ, Chae KY. Obstructive sleep apnea syndrome in children: Epidemiology, pathophysiology, diagnosis and sequelae. Korean J Pediatr 2010; 53: 863-871.

8. Kulaga Z, Litwin M, Grajda A, et al. Oscillometric blood pressure percentiles for Polish normal-weight school-aged children and adolescents. J Hypertens 2012; 30: 1942-1954.

9. National High Blood Pressure Education Program Working Group on High Blood Pressure in Children and Adolescents. The fourth report on the diagnosis, evaluation, and treatment of high blood pressure in children and adolescents. Pediatrics 2004; 114: 555-576.

10. Kulaga Z, Grajda A, Gurzkowska B, et al. Centile charts for blood pressue assessment in children and adolescents aged 3-18 years. Stand Med Pediatr 2013; 1: 22-30.

11. Kulaga Z, Litwin M, Grajda A, et al. Distribution of blood pressure in school-aged children and adolescents reference population. Stand Med Pediatr 2010; 7: 853-864.

12. Urbina E, Alpert B, Flynn J, et al. Ambulatory blood pressure monitoring in children and adolescents: recommendations for standard assessment: a scientific statement from the American Heart Association Atherosclerosis, Hypertension, and Obesity in Youth Committee of the council on cardiovascular disease in the young and the council for high blood pressure research. Hypertension 2008; 52: 433-51.

13. Wuhl E, Witte K, Soergel M, et al. Disttribution of 24-h ambulatory blood pressure in children: normalized reference values and role of body dimensions. J Hypertens 2002; 20: 1995-2007.

14. Touboul P-J, Hennerici MG, Meairs S, et al. Mannheim carotid intima-media thickness and plaque consensus (2004-2006-2011). An update on behalf of the advisory board of the 3rd, 4th and 5th watching the risk symposia, at the 13th, 15th and 20th European Stroke Conferences, Mannheim, Germany, 2004, Brussels, Belgium, 2006, and Hamburg, Germany, 2011. Cerebrovasc Dis 2012; 34 : 290-296.

15. Doyon A, Kracht D, Bayazit AK, et al. Carotid artery intima-media thickness and distensibility in children and adolescents: reference values and role of body dimensions. Hypertension 2013; 62: 550-556.

16. Castronovo V, Zucconi M, Nosetti L, et al. Prevalence of habitual snoring and sleep-disordered breathing in preschool-aged children in an Italian community. J Pediatr 2003; 142: 377-382.

17. Nisbet LC, Nixon GM, Yiallourou SR, et al. Sleep-disordered breathing does not affect nocturnal dipping, as assessed by pulse transit time, in preschool children: evidence for early intervention to prevent adverse cardiovascular effects? Sleep Med 2014; 15: 464-471.
18. Au CT, Chook P, Li AM, et al. Association between childhood primary snoring and cardiovascular health. Hong Kong Med J 2018; 24: 39-40.

19. Kaditis AG, Alexopoulos EI, Kostadima E, et al. Comparison of blood pressure measurements in children with and without habitual snoring. Pediatr Pulmonol 2005; 39: 408-414.

20. Mirecka J, Mazurek-Kula A, Ostrowska K, al. Left heart ventricle function in children snoring due to adeno-tonsillar hypertrophy. Pediatr Pol 2019; 94: 13-17.

21. Bixler EO, Vgontzas AN, Lin H-M, et al. Blood pressure associated with sleep-disordered breathing in a population sample of children. Hypertension 2008; 52: 841-846.

22. Kang K-T, Chiu S-N, Weng W-C, et al. Analysis of 24-hour ambulatory blood pressure monitoring in children with obstructive sleep apnea: a hospital-based study. Medicine (Baltimore) 2015; 94: e1568.

23. Villa MP, Ianniello F, Tocci G, et al. Early cardiac abnormalities and increased C-reactive protein levels in a cohort of children with sleep disordered breathing. Sleep Breath 2012; 16: 101-110.

24. de Oliveira Soares Stefanini D, de Barros EL, Stefanini R, et al. Comparing the clinical profile of non obese children with sleep apnea and snoring. Braz J Otorhinolaryngol 2012; 78: 22-26.

25. Kuo Y-L, Kang K-T, Chiu S-N, et al. Blood pressure after surgery among obese and nonobese children with obstructive sleep apnea. Otolaryngol Head Neck Surg 2015; 152: 931-940.

26. Apostolidou MT, Alexopoulos EI, Damani E, et al. Absence of blood pressure, metabolic, and inflammatory marker changes after adenotonsillectomy for sleep apnea in Greek children. Pediatr Pulmonol 2008; 43: 550-560.

27. Quante M, Wang R, Weng J, et al. The Effect of Adenotonsillectomy for Childhood Sleep Apnea on Cardiometabolic Measures. Sleep 2015; 38: 1395-1403.

28. Kang K-T, Chiu S-N, Lin Ch-Y, et al. Trajectory of ambulatory blood pressure after adenotonsillectomy in children with obstructive sleep apnea:comparison at three- and six- month follow-up. Sleep Med 2020; 65: 127-133.

29. Marcus CL, Greene MG, Carroll JL. Blood pressure in children with obstructive sleep apnea. Am J Respir Crit Care Med 1998; 157: 1098-1103.

30. Weber SAT, dos Santos VJ, de Oliveira Semenzati G. Ambulatory blood pressure monitoring in children with obstructive sleep apnea and primary snoring. Int J Pediatr Otorhinolaryngol 2012; 76: 787-790.

31. Leung LCK, Ng DK, Lau MW, et al. Twenty-four-hour ambulatory $\mathrm{BP}$ in snoring children with obstructive sleep apnea syndrome. Chest 2006; 130: 1009-1017.

32. Xu Z, Li B, Shen K. Ambulatory blood pressure monitoring in Chinese children with obstructive sleep apnea/hypopnea syndrome. Pediatr Pulmonol 2013; 48: 274-279.

33. Li AM, Au ChT, Ho C, et al. Blood pressure is elevated in children with primary snoring. J Pediatr 2009; 155: 362-368.

34. Ng DK, Wong JC, Chan Ch-H, et al. Ambulatory blood pressure before and after adenotonsillectomy in children with obstructive sleep apnea. Sleep Med 2010; 11: 721-725.

35. Fan H-Q, Li Y, Thijs L, et al. Prognostic value of isolated nocturnal hypertension on ambulatory measurement in 8711 individuals from 10 populations. J Hypertens 2010; 28: 2036-2045.

36. Loredo JS, Nelesen R, Ancoli-Israel S, et al. Sleep quality and blood pressure dipping in normal adults. Sleep 2004; 27: 1097-1103.

37. Davies C, Crosby J, Mullins R, et al. Case-control study of 24 hour ambulatory blood pressure in patients with obstructive sleep apnoea and normal matched control subjects. Thorax 2000; 55 : 7736-7740. 
38. Horne RSC, Yang JSC, Walter LM, et al. Nocturnal dipping is preserved in children with sleep disordered breathing regardless of its severity. Pediatr Pulmonol 2013; 48: 1127-1134.

39. Lee Y-H, Kweon S-S, Choi BY, et al. Self-reported snoring and carotid atherosclerosis in middle-aged and older adults: the Korean Multi-Rural Communities Cohort Study. J Epidemiol 2014; 24: 281-286.

40. Iannuzzi A, Licenziati MR, De Michele F, et al. C-reactive protein and carotid intima-media thickness in children with sleep disordered breathing. J Clin Sleep Med 2013; 9: 493-498.

41. Witkowska M. Patomechanizm powikłań w nadciśnieniu. Nadciśn Tętn 1999; 3: 65-72.

42. O'Rourke M. Arterial stiffness, systolic blood pressure, and logical treatment of arterial hypertension. Hypertension 1990; 15: 339-347.

43. Grygalewicz J, Jackowska T, Mazurkiewicz H, et al. Zaburzenia oddychania u dzieci chrapiących w czasie snu, w świetle badań polisomnograficznych. Post Nauk Med 2011; 24: 1032-1037.

44. Øverland B, Berdal H, Akre H. Obstructive sleep apnea in 2-6 year old children referred for adenotonsillectomy. Eur Arch Othorhinolaryngol 2019; 276: 2097-2104.

45. Malakasioti G, Alexopoulos EI, Batziou N, et al. Frequency of moderate-to-severe obstructive sleep apnea syndrome among children with snoring and blood pressure in the hypertensive range. Pediatr Nephrol 2020 Mar 30. doi: 10.1007/s00467-020-04544-0 [Online ahead of print]. 